\title{
Research on Criminal Reconciliation in Ethnic Minority Areas
}

\author{
Lu Tong \\ University of Electronic Science and Technology of China \\ Chengdu, China
}

\begin{abstract}
Criminal reconciliation in China's ethnic minority areas is heavily influenced by national customary laws based on the implementation of national laws. Criminal reconciliation operations in ethnic minority areas have distinct ethnic characteristics. The study of criminal reconciliation in ethnic minority areas is not only conducive to protecting the interests of people in ethnic minority areas, promoting national unity and stability, but also conducive to national harmony and stability and the construction of the rule of law in the country. This paper mainly explores the form of criminal reconciliation in ethnic minority areas, and then puts forward suggestions to improve the operation of criminal reconciliation in ethnic minority areas.
\end{abstract}

Keywords-criminal reconciliation; customary law of minorities; criminal justice

\section{INTRODUCTION}

With the advancement of China's judicial reform, criminal reconciliation in ethnic minority areas has received great attention from the legal theoretical and practical circles in China. The research on criminal reconciliation in ethnic minority areas has important practical significance: (1) Ethnic minority criminal reconciliation is conducive to the fulfillment and implementation of the criminal policy of leniency and strictness. The criminal policy of leniency and strictness requires that different treatment should be implemented according to the specific circumstances of the crime. The public security organs, procuratorial organs, and courts in ethnic minority areas should fully consider the results of reconciliation of criminal disputes in accordance with their habits within the nationality and should treat the offenders with leniency. (2) The customary reconciliation method used in the practice of criminal reconciliation in ethnic minority areas has eased the rigidity of China's enactment law. Resolving the inherent malpractice of our country's legislation law can effectively restore the social relations damaged by crime, which is conducive to advancing China's judicial reform. (3) Criminal reconciliation of ethnic minorities is conducive to the implementation of the system of regional ethnic autonomy, making ethnic minorities prosperous and promoting national unity. (4) Criminal reconciliation in ethnic minority regions is conducive to the comprehensive construction of a harmonious society. Criminal reconciliation of ethnic minorities uses its characteristic operating methods to resolve disputes between the two parties in criminal cases, resolve hatred between the two parties, and restore damaged social relations, which is conducive to the construction of a harmonious society. In view of the uniqueness of criminal reconciliation in minority areas, this paper will discuss the following issues in depth: (1) What is the status of criminal reconciliation in ethnic minority areas? (2) What are the problems in criminal reconciliation in minority areas? (3) How to perfect criminal reconciliation in minority areas? Before discussing the above issues, the author will make an investigation of the status of criminal reconciliation in ethnic regions.

\section{Status OF CRIMINAL RECONCILIATION IN ETHNIC MINORITY AREAS}

Due to geographical location, cultural traditions, religious beliefs, etc., ethnic regions mostly adopt native criminal reconciliation methods rather than statutes to settle criminal disputes. However, with the advancement of judicial reform in China, the judicial practice of criminal reconciliation in ethnic minority areas present the characteristics that the official statutory law and the customary law of ethnic minorities together serve as the legal basis for criminal reconciliation. Therefore, the author believes that the form of criminal reconciliation in ethnic minority areas can be roughly divided into three types.

\section{A. Native Customary Law Dominates}

The first is the criminal reconciliation between the two parties who are the subjects of disputes in the ethnic areas and solve the conflicts privately according to their local customary laws. For example, the Yi People are the most common Degu mediation. After the criminal case occurred, both the parties resolved it by themselves and the mediation between the families and branches did not satisfy the parties, and the parties would ask Degu to mediate. Degu mediation will generally involve the families of the parties to the dispute. Under the leadership of the heads of both sides of the dispute, the two sides conducted reconciliation negotiations to achieve the purpose of eliminating hatred between the two families. The Degu mediation of criminal disputes generally goes through the following procedures: (1) The selection of Degu mediator. As the mediator, Degu is usually more than two, the number of Degu invited by both the perpetrator and the victim should be equal. In addition, Degu's own morality, prestige, and credibility should be 
recognized by both parties. (2) Determine the place of mediation. The mediation place is generally selected by both parties in a spacious open-air venue that is satisfactory to both parties, and the parties are seated at a certain distance between the two places. (3) Conduct factual inquiry and evidence investigation. The parties were far apart, and Degu passed information, listened to the opinions of both parties, produced evidence, and will be cross-examined by both parties. If the parties have disputes over facts or evidence, they can confront each other. (4) Propose methods for dispute resolution. After investigating the merits of the case, Degu will propose a solution to the dispute based on customary law and precedent. And solicit opinions between the victim and the perpetrator, find a plan that may satisfy both parties, and persuade the parties to accept the plan before the parties. (5) Conduct the closing ceremony. On the day or the next day after the parties settled, the parties would jointly contribute money to have a banquet with Degu and related personnel for a "harmonious meal." Under the leadership of Degu, the family leaders of both parties will toast each other in order to express their blessings to each other. After the dispute resolution solution was implemented, the parties to the dispute exchanged visits under the leadership of the house leader, and the Degu mediation process was totally completed. But in practice these five steps are not performed strictly according to the procedure. Throughout the Degu mediation process, there was no shadow of the national public security organs, procuratorial organs, and people's courts, and only relying on Degu to rely on their own knowledge of the Yi customary law and their experience in mediation of criminal disputes to resolve criminal cases. Although the operation of this type of criminal reconciliation is rough and casual compared with the requirements of meticulous national statutory laws, people in ethnic minority areas are still more willing to use the customary law of ethnic minority for criminal reconciliation to resolve criminal disputes.

\section{B. "Official" Enactments Compromise National Customary Law}

The second is under the compromise of the enactment law to the national customary law, the "official" enactment law is used to carry out criminal reconciliation. In this mode of criminal reconciliation in ethnic areas, the judiciary has played an important role. This mode of dispute settlement is divided into two steps: the first step is to investigate the defendant's criminal responsibility and convict and sentence the defendant; the second step is to use the customary laws of ethnic areas to eliminate the grievances through reconciliation negotiation and make the conflict possible to solve. Although national enactments are operating steadily in ethnic minority areas, customary national laws are still having a role, and their impact is even greater than national enactments. Even if the judiciary plays a role, the ultimate result is often far from the provisions of the criminal law because the victim and his family's request for mitigating or exempting the defendant from criminal punishment.

Case: At around 14 o'clock on May 29, 2008, the defendant Cuo Dejie and the villager Xia Wujia rode a motorcycle to the village 's Xian Muzang's story to buy gasoline. The two parties disputed over the price. When the victim's son-in-law Rousai came to see him, he picked up a stone and threw it at the defendant. Cuo Dejie missed it, so the defendant fought with him and was persuaded by Xia Wujia and Zhuomajie who had arrived in the news. The defendant and Xiawu's family left by bicycle. When approaching the pasture of Gengjie's meadow, Xian Muzang and his son-in-law overtook him. The defendant and Xian Muzang again had a dispute. The defendant picked up a stone from the ground and threw it to Xian Muzang. The stone hit the left side of the victim's head and he felt to the ground. Later, the defendant's family and the victim's relatives sent the victim to Qinghai Provincial People's Hospital. Despite rescue efforts, he died on July 1, 2008. The Haixian People's Court of Hainan Tibetan Autonomous Prefecture of Qinghai Province found that the defendant, Cuo Dejie, was guilty of intentional injury and sentenced to three years in prison. The accused was dissatisfied and appealed. The Hainan Tibetan Autonomous Prefecture Intermediate People's Court heard that the defendant was under 18 when he committed the crime; he was able to surrender himself after the crime; it was a first-time crime with a small subjective malignancy, a good guilty attitude, and a certain confession; after the crime was committed, his relatives actively compensated the victims' relatives for economic losses of RMB 1.09 million, and received full understanding from the victims' relatives. The relatives of the victims also demanded that the appellant be lightened or be exempted from criminal punishment. According to the facts of the crime, the nature of the crime, the circumstances and the degree of harm to the society, the appellant was determined, the offence of intentional injury of Cuo Dejie was sentenced to 3 years in prison and 4 years in probation.

Judging from the results of this case, the settlement of the dispute between the defendant and the victim's family essentially involves two parts. The first part is to follow the provisions of China's criminal law to investigate the criminal responsibility of the accused. The second part is to comply with the basic requirements of local "life-loss" customary law. The defendant compensates for the loss, the parties and their families reach a settlement, and the victim's family asks the court to reduce or avoid criminal punishment. In the practice of criminal justice in ethnic minority areas, there are many cases where national legislation similar to the above cases compromises with customary national law. People in ethnic minority areas rely more on the use of reconciliation in national customary law to settle criminal disputes than official legislation.

\section{Official Enactments Dominate}

The third is criminal reconciliation led by the government. For example, the "prosecution and docking" implemented in the Liangshan Yi area. Prosecution docking refers to the working mechanism of procuratorial organs relying on the mediation mechanism of social contradictions and disputes, and using mediation methods to resolve various contradictions and disputes in the procuratorial link under the guidance of the harmonious judicial concept. 


\section{CONFLICTS BETWEEN CRIMINAL RECONCILIATION AND CRIMINAL LAW IN ETHNIC MINORITY AREAS}

The provisions of criminal reconciliation and criminal legislation applicable to ethnic minority areas are both means for reconciling criminal disputes, and they share a common core of punishment for crimes and repair of relations. Although the application of criminal reconciliation in ethnic minority areas is an effective means to successfully resolve the criminal reconciliation in ethnic minority areas through long-term practice in the unification of national enactment law and national customary law. However, because of the inherent problems of our country's official methods, which are contrary to the characteristics of local methods, disconnected from minority areas, and lack of identity and authority in minority areas. Therefore, there is a conflict between the official methods of criminal reconciliation in ethnic areas and national customary law in various aspects, which leads to a large number of problems in the practice of criminal reconciliation in ethnic areas.

\section{A. Scope of Application}

With regard to the scope of application of criminal reconciliation cases, the scope of criminal reconciliation in ethnic regions is far greater than the scope of application of criminal reconciliation in official methods. The scope of cases applicable to criminal reconciliation determined by the new Criminal Procedure Law is limited to those suspected of violating the personal rights of citizens, democratic rights, crimes of property caused by civil disputes, cases that may be sentenced to three years' imprisonment, except dereliction of duty, cases of negligent crime may be sentenced to fixedterm imprisonment of not more than seven years. The defendant had excluded the crime of intentional crime within five years from the scope of settlement. In contrast, the application of criminal reconciliation for ethnic minorities, such as the customary law of "compensating lives", which compensates for human lives with money, reflects that cases of intentional homicide in national customary law can be reconciled. Field investigations by scholars also found that the criminal cases mediated by "Degu" even include deaths caused by intentional injuries of more than ten years, life imprisonment or death in accordance with the Criminal Law. The narrow scope of the application of national law's criminal reconciliation will arouse the people's dissatisfaction in the minority areas who hope to keep silent, and they are more willing to choose their own customary law for reconciliation.

\section{B. Criminal Facts Identification Standard}

In terms of the standards for determining the facts of a crime, the customary law of the nation makes the determination of the facts of the crime relatively rough when operating criminal reconciliation in ethnic areas. According to China's official statutory law, the basis of any stage in criminal reconciliation proceedings is that evidence that can prove the facts of the crime has been seized. The law requires that criminal reconciliation must be initiated only after the investigating authority has established the facts of the case in strict accordance with the procedures and has 
obtained sufficient evidence. The criminal settlement in the national customary law of our country has relatively rough identification of criminal facts. Without investigating authorities to carry out a careful investigation of the facts of the crime in accordance with strict procedures, it is inevitable that there will be missing evidence, which may lead to situations that remain unknown in the case. In addition, because of their customs, religious beliefs, and other reasons, the standards for determining crimes are different from the standards for determining crimes in other regions. If the standards for criminal determination in accordance with the official statutory law, it is not conducive to the restoration of the relationship between the two parties to the case, and even leads to the people's resistance to the law in the minority areas. If the customary law of minority areas is fully followed, it may lead to miscarriage of justice.

\section{Settlement Rules}

Regarding the rules of settlement procedures, the rules of settlement procedures of the official enactments are more specific and strict. The official methods of our country stipulate the scope, conditions, content of reconciliation and procedures of reconciliation. In terms of the reconciliation procedure, not only the main body of the reconciliation, the method of reconciliation, the content of the reconciliation, but also the content of the people's procuratorate to examine the voluntary and legality of the reconciliation. The operation of criminal reconciliation in ethnic areas has a distinctive national character. This method of dispute reconciliation based on national customary law is relatively looser and autonomous. There is no written legal requirement. There is no strict limitation on the scope of the settlement, and the scope of reconciliation is relatively broad.

In terms of reconciliation methods, criminal reconciliation in ethnic minority areas has national characteristics, and there are no strict rules on reconciliation procedures, which are relatively arbitrary. Participants in the reconciliation are generally the victims and their relatives and perpetrators and their relatives, as well as the patriarchs and leaders of both parties. The presidency of the settlement is generally chosen by the highly respected people or the patriarchs and leaders of both parties who have agreed to the two parties, such as the "Degu" mediation of the Yi People, and the mediation of the chieftain of the Tibetan people. Because the determination of criminal facts in criminal reconciliation cases in ethnic areas is rough and arbitrary, there is no rule of evidence. Moreover, the reconciliation between the two parties is generally voluntary because of their own national culture and other reasons. The disputes have their own national ideas and habits with national characteristics, which are different from national laws and even contrary to national laws. Therefore, no examination is required in terms of evidence, parties' willingness to settle, and legality. Criminal reconciliation in ethnic minority areas does not require the intervention of public security organs, procuratorial organs, and people's courts. The content of reconciliation is generally economic compensation and responsibility for behavior. Therefore, there is no limit to the scope of customary law that can be negotiated during reconciliation. After the settlement is concluded, agreement documents such as settlement agreements are generally lacking.

\section{Reconciliation Effect}

In terms of the effectiveness of reconciliation, reconciliation under national official regulations is generally more effective in the legal sense, while reconciliation based on national customary law is more effective in the real sense. The criminal reconciliation under the adjustment of state official methods has national law as the support and has legal effect among the parties to the criminal dispute. China's criminal procedure law stipulates that criminal suspects and defendants may obtain legal benefits through criminal reconciliation, such as leniency treatment of criminal convictions and sentencing, established criminal suspects, defendants who seriously confess their guilt, and apologize to the victims. The dynamic mechanism of reparation and compensation will help to motivate criminal suspects and defendants to seek proactive understanding and reach a criminal settlement agreement. However, in ethnic areas, the national law's treatment of convictions and sentencing leniency through reconciliation has no effect. For example, studies by scholars have shown that in the eyes of traditional Tibetans, the penalty of depriving criminals of their right to life is not the most severe punishment. Similarly, in the eyes of traditional Yi People, depriving criminals of life is not as severe as punishment for "crippling offenders." In the eyes of the people in ethnic minority areas, the punishment method similar to "firing out family members" in customary law is stronger than national law. Therefore, if it is necessary to punish the perpetrators in criminal cases, people in ethnic minority areas are more willing to follow their customary laws to punish them. However, compared with the leniency of the outcome of the disputes after criminal reconciliation under the adjustment of national laws, the criminal suspects and defendants in some cases are still punished. People in ethnic minority areas are more inclined to use customary law to settle themselves.

\section{E. The Finality of Dispute}

In terms of the finality of the dispute, criminal reconciliation under national official laws is more final. Criminal reconciliation under the adjustment of official national laws has always been used as a basis for sentencing in criminal procedures before sentencing, that is, parties can choose to settle in any stage of investigation, review, prosecution, and trial, which can affect the law on the processing results of the next stage. But the final result lies in the decision of the judiciary. After the criminal liability of the perpetrator is determined and the related rights and obligations relationship is delivered for execution, the perpetrator's behavior will no longer be re-evaluated by national justice, that is, the principle of one thing and no reason will be followed, and the same criminal fact cannot be restarted against the same perpetrator. The decision of the national judiciary is final in criminal reconciliation. The criminal reconciliation under the adjustment of national customary law is completely out of the control of state public security organs, procuratorial organs, and people's courts. 
Due to the lack of legality and effective normative supervision of the start-up and operation procedures, and the settlement of the criminal liability of the offender, this kind of reconciliation method has not been recognized by the national law in terms of status, and the processing result does not generate a judgment. It is also impossible to restrict national justice from "duplicate evaluation" of such mediation criminal cases. The result of this non-final treatment has led to the victim or third party's threats to the offender in the future, such as reporting and exposing. This has the counter-effect of protecting the offender and has even more far-reaching negative effects.

\section{CONCLUSION}

There is a contradiction between the official statutory law and ethnic customary law in the operation of criminal reconciliation in ethnic minority areas. To improve the operation of criminal reconciliation in ethnic minority areas, it is necessary to integrate and adjust the enacted law and national customary law from the aspects of procedure and substantive law from two aspects: procedural and substantive law. Through the improvement of supporting measures for criminal reconciliation in ethnic minority areas, people's trust in official methods has been increased.

\section{A. Exercising the Criminal Law Adaptation Right in the Substantive Law Field}

Scientifically exercise the right to adapt criminal law in the field of criminal substantive law. The national enactment law is a set of universally applicable norms. China is a unified multi-ethnic country. Each nation has a unique traditional culture and its own customary law formed through long-term life practice. The state cannot consider all ethnic groups from detailed situation to make laws. However, when formulating laws, the state will consider national characteristics to varying degrees and attach importance to the protection of minority rights and interests. Therefore, the predicament of the national criminal customary law is solved by providing some special provisions such as possible adaptations and supplements for the socialist legal system of our country to properly reflect the characteristics of ethnic minorities. For example, article 116 of the Constitution, article 73 of the Legislation Law, article 90 of the Criminal Law, and article 6 of the Law of Regional National Autonomy provide special provisions on supplementary provisions for ethnic autonomous areas. These regulations make the customary laws of ethnic minorities integrated into China's socialist criminal rule of law system through the form of adaptation and supplementary regulations. National law stipulates that, if the national autonomous areas cannot fully apply the provisions of the criminal law, the people's congresses of the autonomous regions or provinces may formulate modifications or supplementary regulations based on the political, economic, and cultural characteristics of the local ethnic groups and the basic principles provided by the criminal law, and report them to the whole country. The Standing Committee of the People's Congress approved the implementation. Thus promote the customary law of minorities' criminal reconciliation to be compatible with national legislation.

On the one hand, legislative bodies in ethnic minority areas should be careful in their legislation. In the process of formulating adaptations or supplementary regulations in accordance with the law, the autonomous agencies of the ethnic minority autonomous regions or the people's congresses of the provinces must consider the national legislation. In addition, it is necessary to combine the ethnic policies of the party and the country, and use the experience of judicial practice as the basis to extract the essence of the ethnic customary law and remove its dregs. Autonomous regions or provincial people's congresses should use the criminal law's right of adaptation in a scientific and prudent manner, and specially organize investigation teams to conduct legislative investigations. The author believes that in the criminal law adaptation of legislation, the first thing needed to pay attention to is the regulation of the scope of criminal reconciliation in ethnic minority areas is in line with the scope of criminal reconciliation in the statute of the state. Authorities in autonomous regions or provinces should appropriately reduce the scope of application of criminal reconciliation and reduce it to minor cases occurring in the civil society. Murder cases, drug trafficking cases, and other cases that have serious and adverse effects should be provided to public security organs, procuratorates, and people's courts for handling according to law, so as not to obscure sin and non-sinlimit.

On the other hand, the party and the state should ensure the effective implementation of the criminal law's workaround. National laws should clearly recognize the customary laws of ethnic minorities in order to protect national rights and interests. Minority areas have customary laws that differ from criminal legislation because of their national characteristics and customs. The state should recognize the outstanding parts of these customary laws and respect the national culture and beliefs. In terms of punishment for crimes, the death penalty is not the harshest punishment in some ethnic cultures. For example, the expulsion of the Yi People to the Yi People is greater than the deprivation of life and freedom. China's statutory law should scientifically and appropriately recognize and accept this customary approach to ethnic minorities. The adaptation of national customary law to China's socialist legal system requires the joint efforts of the state and ethnic regions.

\section{B. Integration of National Customary Law and Criminal Procedure Law in Procedural Law}

For the integration of national customary law and criminal procedure law in the field of criminal procedure law, in terms of the procedure of criminal reconciliation, the procedure of criminal reconciliation stipulated by Chinese law is more complete than the procedure of criminal reconciliation in ethnic minority areas. Criminal reconciliation in ethnic minority areas is generally presided over by prestigious leaders of various ethnic groups or prestigious persons such as patriarchs, without the intervention of the judiciary, and the procedures are relatively loose and casual. Although the method of 
reconciliation is relatively easy and has national characteristics, it cannot guarantee the fairness and justice of the outcome. Therefore, in the field of criminal procedure law, the criminal reconciliation procedure in ethnic areas must be in line with the criminal reconciliation procedure prescribed by the state. First, in the initiation procedure, it is necessary to ensure that both parties to a criminal dispute agree to settle. First of all, the parties shall voluntarily propose a settlement within the scope of the settlement. And provide the public security organs, procuratorial organs, and people's courts with materials that voluntary settlement is not forced by one party or interfered by a third party. Second, the method of reconciliation retains the method of reconciliation of customary law in ethnic regions. Authorities such as heads or patriarchs of ethnic minorities are allowed to act as mediators to preside over mediation. There are various methods of criminal reconciliation. In addition to the mediators of national disputes, there are many legal workers. Criminal reconciliation in ethnic areas can also have some innovations in the choice of mediators. In addition to relying on the mediation of chiefs and patriarchs, the choice of mediators can be extended to mediators and people's mediators in official institutions. Third, after reaching a settlement, it should be submitted to the judicial organ for review and record. And the judiciary produces a settlement agreement and keeps the documents, thus to ensure the effectiveness of the settlement.

\section{Improving Supporting Measures}

Criminal reconciliation in ethnic minority areas also has its own lack of supporting measures. To improve criminal reconciliation in ethnic minority areas, we must also pay attention to the improvement of supporting measures. The author believes that the victim compensation system and the deferred prosecution system and the community correction system are all suitable supporting means for establishing and improving the criminal reconciliation in minority areas.

First is to establish and improve victim compensation systems in ethnic minority areas. At present, China's criminal justice system has not established a good victim protection system. In the final analysis, reconciliation is more about protecting the offenders in criminal cases. This is even more the case in minority areas. Due to the wide scope of the application of reconciliation in ethnic minority areas, many cases have occurred after the murders, which have caused people to pass the reconciliation, and the major events have been reduced to small matters. Under the protection of criminal reconciliation in ethnic regions, the judicial authorities have avoided their responsibility to be investigated. The victims and their relatives who settled with them also received limited compensation after consultation. In the process of reconciliation, conflicts between the two parties will inevitably lead to conflicts. The victims and even their families cannot obtain the personal safety guarantee from such customary criminal reconciliation, not to mention that the reputation and social relations of the victims and their families will be more difficult to guarantee in the future. In the improvement of criminal reconciliation in minority areas, the state should establish a victim compensation system. When applying for state compensation, a criminal victim shall show the court's judgment on the case and a written application to the relevant agency. Compensation is made by the State Compensation Agency based on the court's ruling.

Second, a deferred prosecution system should be established in ethnic minority areas. The development of China's deferred prosecution system still needs to learn from foreign advanced experience. At present, some regions of China have begun trials of criminal deferral systems. For example, the People's Procuratorate of Gejiu City, Yunnan Province implemented a deferred prosecution system in 2001. In 2005, 29 minor offenders who were under prosecution were deferred and set a test after the trial, 28 of these offenders did not have a record of renewed or continuing crimes, and the lawsuit was terminated against them. The author believes that the establishment of a deferred prosecution system in ethnic minority areas is essentially an effective way to weaken the conflict between the state's enacted law and national customary law. Supervise the execution of the content of the reconciliation agreement and the remorse of the criminal suspects during the period of suspended prosecution. It is suggested that not to prosecute the integration and integration of the customary laws of ethnic minorities to meet the satisfaction of people in ethnic regions.

Third is to improve the community correction survey system in ethnic minority areas. Based on their customary laws, ethnic minorities are more suitable for the development of community corrections. The chiefs and patriarchs within the clan have some understanding of their clan and are authoritative, and it is easy to persuade criminal suspects. The implementation of community corrections in ethnic areas should be reflected in criminal reconciliation and combined with national customary law. The mediator or patriarch and chief leader began to educate the criminal suspects during the settlement of criminal disputes. On the one hand, they made them sincerely confess their guilt and recognize their mistakes; on the other hand, they monitored the performance of the criminal suspects by implementing the settlement agreement.

\section{REFERENCES}

[1] Feng Lu, Li Xin, Research on the Operation of Criminal Reconciliation in Liangshan Yi Nationality Area [J]. Journal of Southwest University for Nationalities (Humanities and Social Sciences), 2016.37 (12) 108-112. (in Chinese)

[2] Su Yongsheng, Regional Criminal Rule of Law and Logic [M]. Beijing: Beijing People's Publishing House, 2013, P150. (in Chinese)

[3] $\mathrm{Xu}$ Tonglu, Establishing "Prosecution and Docking" Working Mechanism to Effectively Solve Contradictions and Disputes [J]. People's Procuratorate, 2007.24 (12) 44-46. (in Chinese)

[4] Ma Yinglin, Zhang Jie. A Comparative Analysis of the Judicial Practices of the Yi Criminal Law and the National Criminal Law Taking the Judicial Practice of Yi People's Murder Cases in Liangshan as an Example [J]. Ethnology 2012.3 (5) 60-67. (in Chinese)

[5] Wu Shanshan, Gao Lu. On the Integration of National Criminal Law and Minority Customary Law [J]. Journal of Yunnan Institute of Socialism 2012.5 (3). 85-86. (in Chinese) 